\title{
Towards a Science of Adaptation that Prioritises the Poor
}

\author{
Andrew Challinor
}

\begin{abstract}
1 Model-based prediction
Many of the advances in climate science over the last few decades have been manifest in climate models. Realism and skill have increased over time - though not necessarily proportionally - as more processes have been parameterised. Land surface processes are among the most recent additions and these lend themselves naturally to the simulation, within the climate model, of derived quantities such as crop yield (Osborne et al. 2007). This is part of a broader extrapolation of climate variables, which need not happen within the climate model, into impacts such as those on agriculture (Challinor et al. 2004) and health (Thompson et al. 2006). Climate impacts research is a growth area, with emerging methodologies and resources (Challinor et al. 2008a).
\end{abstract}

A particular area of growth in climate science over the last decade is in the use of ensembles, where one or more climate models are used to quantify the inherent uncertainty in climate prediction (Collins and Knight 2007; Lejenäs 2005). This is the result of both ongoing increases in computer power and the realisation that increased realism alone is insufficient to maximise forecast skill. There is the potential to increase the skill of seasonal forecasts and also to produce forecasts seamlessly at a range of timescales (UCRP 2008), but how useful are these developments likely to be in supporting pro-poor adaptation?

Climate impacts research can increase the relevance of climate forecasts. However, as explained in the third section here, care should be taken to strike the right balance between relevance and accuracy. Also, models of climate impacts should be used with appropriate consideration of their limitations. There can be a tendency within parts of the scientific community to view models as the repository of scientific knowledge, when in fact the fundamental source of knowledge is people: the scientists themselves, practitioners and stakeholders. This paradigm, whereby models are trusted principally because of the many independently tested equations they contain, can result in over-confidence in results. When it comes to equations in a numerical model, more is not necessarily better. $A$ model with many equations will have many associated parameters.

Finding the correct value for every single parameter is unlikely, especially when parameters are not directly measurable, and/or represent complex interactive processes with non-reproducible results (both of which often occur in biological systems). This difficulty in constraining a large set of parameters with only limited observations increases the risk of getting the right answer (model output equals observations) for the wrong reason (the model has been overly 'tuned').

Consider as an example, a crop model with yield as its principal output. The model may perform well when the many parameters of the model are tuned to observed yields, while performing poorly in the absence of this tuning - exactly the circumstances when the model is needed and implicitly trusted (since there are no observations of yield). Having fewer parameters can reduce the risk of over-tuning (Cox et al. 2006). This pragmatic approach can result in a number of models that give a good fit to observations, so that there may be more than one acceptable model (Beven 2006). In crop modelling, this approach has the advantage that it simulates at a systems level that is near to crop yield, which is the variable of interest (Sinclair and Seligman 2000). Whichever approach is taken, model tuning (or calibration, as it is more commonly known) is an important step in producing a viable model. However, as outlined above, and as explored in more 
detail by Challinor and Wheeler (2008a), the relationship between model complexity and calibration should always be carefully explored.

\section{A framework for informing adaptation} Challinor (2008) discusses the conditions under which forecast information can usefully affect decisions made by farmers, extension workers, governments or international organisations. Forecasts should be: (i) reliable, (ii) in appropriate context, (iii) relevant, and (iv) perceived to be useful.

(i) Reliable: While inherent uncertainties mean that a positive outcome may not result every time a forecast is acted upon, overall benefit should emerge over time. Thus, uncertainty should be known to some degree of accuracy, and a risk management approach should be taken. Reliability is a formal and well-defined concept within seasonal probabilistic weather forecasting: for a perfectly reliable system, half of all forecasts stating a 50 per cent chance of rain are followed by rain. At longer lead times, such as for climate projections, reliability cannot be quantified. At any lead time, unreliable projections are likely to result in incorrect assessment and management of risk.

(ii) In appropriate context: $\mathrm{A}$ holistic, systems approach should be taken, so that all the factors affecting the decision are accounted for. Many of these factors will be uncertain, and their interactions will produce further uncertainty. Adaptation options are needed that take account of the full range of stresses on the poor. This is particularly challenging, since the needs of the poor are highly diverse, both geographically and between people within a given region (Morton 2007). Hence, studies of decision support for cropping systems in different parts of the globe are likely to differ in their conclusions (Gadgil et al. 2002; Hansen 2005). The condition of holism implies a need for knowledge and research from more than one discipline.

(iii) Relevant: The variables, spatial scale and lead time of climate projections should be appropriate to the decision in question. A common problem with the use of climate model output is that the resolution is too coarse. Where crop yield forecasts are needed, this disparity in spatial scale can be overcome by either using location-specific decision support models (Boote and Jones 1998) with downscaled climate model output models (Hansen 2005; Southworth et al. 2002), or through a 'large area' approach, where climate impacts are simulated on the climate model grid. This latter method may use empirical (Iglesias et al. 2000) or processed-based (Challinor et al. 2004) models. Empirical methods can introduce significant errors through the linearisation of the equations for crop yield (Challinor et al. 2006) and/or the use of monthly data, which cannot account for sub-seasonal variability in weather. Process-based large-area models, while being potentially prone to aggregation error (Hansen and Jones 2000), have shown promising results in current climates (Osborne et al. 2007; Chee-Kiat 2006; Challinor et al. 2005a,b).

(iv) Perceived to be useful: Unless this condition is met, the forecast will not be acted upon. The information given should therefore be credible and legitimate (Patt and Gwata 2002). This implies that pro-poor adaptation should be based upon - not merely relevant to - the needs of the poor. Since these needs will vary geographically, with sector, and with social structure, it is essential that the potential benefactors of scientific advances, and the resulting information that supports adaptation, are involved in adaptation studies from the start.

The heterogeneity of needs (iv), and of stresses (iii), has profound implications for the ability of science to support pro-poor adaptation. No scientific panacea can exist for the problems of the poor. However, as in all human endeavours, scientists can choose whether or not their work will try to prioritise the needs of the poor.

\section{Prioritising the poor: top-down or bottom-up approaches?}

Pro-poor adaptation supports livelihoods by finding effective strategies to cope with environmental change, and by addressing the local and institutional barriers to the use of these strategies. In doing so, it must deal both with the differentiated nature of poverty and the implications of uncertainty in the assessments of environmental change. How can the scientific advances outlined in the first section best serve the needs of the poor? Many of these advances are technologically driven ('top-down'), rather than needs-driven ('bottom-up'). While it is now common for research and development projects in climate science to incorporate a component on applications 
and/or impacts, it is not clear that this goes far enough towards addressing real-world needs. Washington et al. (2006) argue that, in Africa, developing coping mechanisms for climate variability is the logical first step in dealing with climate change. This requires data, which is a serious constraint on African climate science. Hence, it may be more weather stations, rather than more climate simulations, that are needed in order for scientific understanding, and the coping capacity that it informs, to grow. Observations can also have more direct benefits, as part of a programme of participatory research. For example, in Colombia rain gauge data has been used to correct farmers' assessment of the principal growing season (Oberthür, personal communication 2002). The issue of data availability is one example of how science may be allied more closely with the needs of the poor. It suggests that science might be better tailored to needs by being less driven by technological advancement. Instead, one might start with the needs of the poor, and carry out science accordingly.

\section{Starting from societal needs has implications for} relevance: a scientific study may not be relevant beyond the region in which it was conducted. Relevance is also affected by the methods used. In practice there is often a trade-off between relevance and accuracy (Challinor et al. 2008a). Quantitative methods may be able to simulate climate, and even link it to crop yield; however, the relevance of these simulations to a farmer may be low. In contrast, farming systems develop highly relevant, but perhaps inaccurate, information systems. These are often in the form of proverbs, such as 'Uttara chusi, yattara gampa' (Wait for rainfall during September 13-26; if it fails, leave the place), from south India. While it is no doubt true that the Uttara rains are important for crops, the accuracy of this proverb will depend on the crop, the planting date, crop management and development of the season preUttara. Wheeler et al. (2005) tested this proverb against their crop model, using both as methods of predicting crop failure. They found their model to be better at simulating the three lowest-yielding years than the proverb. However, this analysis contrasts formal and local knowledge using the constructs of science (empirical measurement of yield and rainfall, simulation models) rather than those of society (livelihoods, income). In other words, such a comparison does not prove that a model is more useful than a proverb; merely that it is more accurate for a given metric of crop productivity, using a given dataset.
Even where scientific information is both accurate and useful, the information often does not reach those who need it, due to poor communication channels. Even where information is available, it is not always used, either because of a lack of resources or because of other barriers. For example, where seasonal forecasts are available, both accuracy and usefulness along with other constraints can limit the uptake of forecast information (Patt and Gwata 2002). The format of forecasts, and their probabilistic nature, can also be barriers to their use. One way around these problems is to have organisations designed specifically to use forecasts, rather than attempt to have them used directly by farmers. Agricultural extension workers and crop insurance schemes are two examples of this. These can be seen more broadly in terms of the mainstreaming of climate information, or 'climate proofing', which are ways of integrating knowledge into decision-making structures.

Such mainstreaming is a top-down concept, reflecting to some degree the order given to the items in the adaptation framework in the second section (reliability, context, relevance, perception). The first two items, reliability and context, are both firmly within the domain of the natural scientist: it is a matter of professionalism for a modeller to produce forecasts that are reliable, and complete in their consideration of the processes involved. Relevance is something that a natural scientist can assess to some degree, though certainly not without engaging others. In short, the concepts become increasingly subjective, something that many natural scientists try and avoid.

How might a more bottom-up framework for adaptation look? Perhaps it would prioritise the perception of usefulness, by focusing scientific effort where the perceived benefit is greatest (e.g. increasing the number of weather stations or setting up insurance schemes). However, just as the scientific community cannot assess relevance without reference to potential beneficiaries, the potential benefit of science can only be assessed in conjunction with knowledge of that science. Perhaps, then, it would prioritise relevance. However, the heterogeneity of needs and of stresses implies geographical variation in the science needed to promote the wellbeing of the poor. Therefore, while there is a useful inherent focus on needs provided by a bottom-up approach, it seems that another perspective is needed for pro-poor adaptation. 


\section{Discipline-driven or issue-driven interdisciplinarity?}

Robinson (2008) argues that issue-driven interdisciplinarity provides a useful paradigm for meeting the needs of society, particularly those relating to sustainable use of resources. Pro-poor adaptation is by its nature driven by a central issue: the needs of the poor. In contrast, discipline-driven interdisciplinarity is based on the sum of the component disciplines, and is therefore likely to be a sub-optimal strategy for meeting the challenges of pro-poor adaptation. What is needed is more than simply applied science; it is fundamental (process-based) needs-driven science that has no regard for current disciplinary boundaries.

An issue-based perspective provides an alternative to bottom-up and top-down approaches. In this paradigm, science is an ongoing two-way conversation that is iterative and integrative, initiated either by researchers or by potential users of information. Such a process involves a needs-based perspective, as outlined in the third section; but since the research is fundamental, as opposed to applied, it also goes beyond this. It can involve issues raised by the scientific community, such as the need to incorporate mitigation actions into adaptation strategies, or how to effectively cycle nutrients in the soil. This second issue, for example, may be informed by decision support crop models, which can be used to determine how much fertiliser to apply. An issuebased perspective is critical here, since in practice, the majority of farmers will not use such systems unless they are actively engaged in dialogue ('discussion support', see Hansen 2005). Similarly, yield forecasting systems (Challinor et al. 2005a) are a scientific tool that, together with appropriate structures and resources for the exchange of information, could be used to mobilise resources and alleviate food shortages in low-yielding years, or to provide advice on crop scheduling.

The need for adapted crops under climate change is another issue that can drive research. Research using crop and climate models can determine the genotypic properties required to adapt to climate change (Challinor et al. 2007a, 2008b; Challinor and Wheeler 2008b), but these must be compared with the full range of existing germplasm (e.g. Challinor 2008), and the work placed in broader context (Challinor et al. 2007b; Howden et al. 2007; Morton 2007; and see above) before adaptation can be adequately informed. The broader context is likely to contain geographically-specific and/or communityspecific requirements. It may include obstacles to the implementation of the recommendations of research. For example, farmers may not have access to the varieties they need, due to external patent ownership, low income or lack of access to local markets. The broader context may also include factors that have remained outside of the research analysis, either because of geographical specificity or because of necessary reductionism in the science. Here, again, an issue-based approach has the potential to include a range of processes and perspectives that would not be present in disciplinebased top-down science.

Given the need for full consideration of context, the most effective way to conduct pro-poor adaptation research may well be to take - from the outset - a holistic view that is informed by engagement and partnership with potential benefactors. Inevitably, these potential benefactors will have much to contribute. This realisation is at the heart of the identification by a major international assessment (IAASTD 2008) of the need for both local and formal knowledge in developing sustainable agriculture. It is time for science to take an issuebased approach to tackling the challenges of sustainability and of pro-poor adaptation. This is more than simply the application of existing science, no matter how 'interdisciplinary' the methods. It demands greater integration across the scientific community, and between scientists and practitioners. In this way, science can be effectively put at the service of the poor. 


\section{References}

Beven, K. (2006) 'A Manifesto for the Equifinality Thesis', Journal of Hydrology, 320.1-2: 18-36

Boote, K.J. and Jones, J.W. (1998) 'Simulation of Crop Growth: CROPGRO Model', in R.M. Peart and R.B. Curry (eds), Agricultural Systems Modeling and Simulation, New York: Marcel Dekker Inc., Ch. 18: 651-92

Challinor, A.J. (2008) 'Developing Adaptation Options Using Climate and Crop Yield Forecasting at Seasonal to Multi-decadal Timescales', submitted to Environmental Science and Policy

Challinor, A.J. and Wheeler, T.R. (2008a) 'Use of a Crop Model Ensemble to Quantify $\mathrm{CO}_{2}$ Stimulation of Water-stressed and Well-watered Crops', Agricultural and Forest Meteorology 148.6-7: 1062-77

Challinor, A.J. and Wheeler, T.R. (2008b) 'Crop Yield Reduction in the Tropics Under Climate Change: Processes and Uncertainties', Agricultural and Forest Meteorology 148.3: 343-56

Challinor, A.J.; Wheeler, T.R.; Osborne, T.M. and Slingo, J.M. (2006) 'Assessing the Vulnerability of Crop Productivity to Climate Change Thresholds Using an Integrated Crop-climate Model', in J. Schellnhuber, W. Cramer, N. Nakicenovic, G. Yohe and T.M.L. Wigley (eds), Avoiding Dangerous Climate Change, Cambridge: Cambridge University Press: 187-94

Challinor, A.J.; Slingo, J.M.; Wheeler, T.R. and Doblas-Reyes, F.J. (2005a) 'Probabilistic Hindcasts of Crop Yield Over Western India', Tellus 57A: 498-512

Challinor, A.J.; Wheeler, T.R.; Slingo, J.M.; Craufurd, P.Q. and Grimes, D.I.F. (2005b) 'Simulation of Crop Yields Using the ERA40 Re-analysis: Limits to Skill and Non-stationarity in Weather-yield Relationships', Journal of Applied Meteorology 44.4: 516-31

Challinor, A.J.; Wheeler, T.R.; Craufurd, P.Q.; Ferro, C.A.T. and Stephenson, D.B. (2007a) 'Adaptation of Crops to Climate Change Through Genotypic Responses to Mean and Extreme Temperatures', Agriculture, Ecosystems and Environment 119.1-2: 190-204

Challinor, A.J.; Wheeler, T.R.; Garforth, C.; Craufurd, P. and Kassam, A. (2007b) 'Assessing the Vulnerability of Food Crop Systems in Africa to Climate Change', Climatic Change 83: 381-99

Challinor, A.J.; Wheeler, T.R.; Slingo, J.M.; Craufurd, P.Q. and Grimes, D.I.F. (2004) 'Design and Optimisation of a Large-area Process-based
Model for Annual Crops', Agricultural and Forest Meteorology 124.1-2: 99-120

Challinor, A.J.; Challinor, T.; Osborne, A.; Morse, L.; Shaffrey, T.; Wheeler, H. and Weller, H. (2008a) 'Methods, Skills and Resources for Climate Impacts Research', submitted to Bulletin of the American Meteorological Society

Challinor, A.J.; Wheeler, T.R.D.; Hemming, D. and Upadhyaya, H.D. (2008b) 'Crop Yield Simulations Using a Perturbed Crop and Climate Parameter Ensemble: Sensitivity to Temperature and Potential for Genotypic Adaptation to Climate Change', submitted to Climate Research

Chee-Kiat, T. (2006) 'Application of Satellite-based Rainfall Estimates to Crop Yield Forecasting in Africa', PhD thesis, University of Reading

Collins, M. and Knight, S. (eds) (2007) 'Ensembles and Probabilities: A New Era in the Prediction of Climate Change', papers of Theme Issue Philosophical Transactions of the Royal Society A365.1857: 1955-2191

Cox, G.M.; Gibbons, J.M.; Wood, A.T.A.; Craigon, J.; Ramsden, S.J. and Crout, N.M.J. (2006) 'Towards the Systematic Simplification of Mechanistic Models', Ecological Modeling 198.1-2: 240-6

Gadgil S.; Rao, P.R.S. and Rao, K.N. (2002) 'Use of Climate Information for Farm-level Decision Making: Rainfed Groundnut in Southern India', Agricultural Systems 74.3, December: 431-57

Hansen, J.W. (2005) 'Integrating Seasonal Climate Prediction and Agricultural Models for Insights into Agricultural Practice', Philosophical Transactions of the Royal Society B360: 2037-47

Hansen, J.W. and Jones, J.W. (2000) 'Scaling-up Crop Models for Climatic Variability Applications', Agricultural Systems 65: 43-72

Howden, S.M.; Soussana, J.F.; Tubiello, F.N.; Chhetri, N.; Dunlop, M. and Meinke, H. (2007) 'Adapting Agriculture to Climate Change', Proceedings of the National Academy of Sciences 104.50: 19691-6

Iglesias, A.; Rosenzweig, C. and Pereira, D. (2000) 'Agricultural Impacts of Climate Change in Spain: Developing Tools for a Spatial Analysis', Global Environmental Change 10.1: 69-80

IAASTD (International Assessment of Agricultural Knowledge, Science and Technology for Development) (2008) Synthesis Report of the International Assessment of Agricultural Knowledge, Science and Technology for Development, www.agassessment.org (accessed 9 July 2008) Lejenäs, H. (ed.) (2005) Special Issue: 'Development of a European Multi-Model Ensemble System for 
Seasonal to Interannual Prediction (DEMETER)', Tellus 57A.3: 217-512

Morton, J.F. (2007) 'The Impact of Climate Change on Smallholder and Subsistence Agriculture', Proceedings of the National Academy of Sciences 104.50: 19680-5

Osborne, T.M.; Lawrence, D.M.; Challinor, A.J.; Slingo, J.M. and Wheeler, T.R. (2007) 'Development and Assessment of a Coupled Crop-climate Model', Global Change Biology 13: 169-83

Patt, A. and Guata, C. (2002) 'Effective Seasonal Climate Forecast Applications: Examining Constraints for Subsistence Farmers in Zimbabue', Global Environmental Change: Human and Policy Dimensions 12: 185-95

Robinson, J. (2008) 'Being Undisciplined: Transgressions and Intersections in Academia and Beyond', Futures 40: 70-86

Sinclair, T.R. and Seligman, N. (2000) 'Criteria for Publishing Papers on Crop Modelling', Field Crops Research 68: 165-72

Southworth, J.; Pfeifer, R.A.; Habeck, M.; Randolph, J.C.; Doering, O.C. and Rao, D.G. (2002)
'Sensitivity of Winter Wheat Yields in the Midwestern United States to Future Changes in Climate, Climate Variability, and $\mathrm{CO}_{2}$ Fertilization', Climate Research 22.1: 73-86

Thompson, M.C.; Doblas-Reyes, F.J.; Mason, S.J.; Hagedorn, R.; Connor, S.J.; Phindela, T.; Morse, A.P. and Palmer, T.N. (2006) 'Malaria Early Warnings Based on Seasonal Climate Forecasts from Multi-model Ensembles', Nature 439: 576-9 Washington, R.; Harrison, M.; Conway, D.; Black, E.; Challinor, A.; Grimes, D.; Jones, R.; Morse, A.; Kay, G. and Todd, M. (2006) 'African Climate Change: Taking the Shorter Route', Bulletin of the American Meteorological Society, October: 1355-66

Wheeler, T.R.; Challinor, A.J.; Slingo, J.M.; Grimes, D.I.F. and Craufurd, P.Q. (2005) 'Forecasting the Harvest: From Proverbs to PCs', The Biologist 52.1: 45-9

WCRP (2008) World Climate Research Programme Position Paper on Seasonal Prediction, World Climate Research Programme Informal Report 3/2008, www.clivar.org/organization/wgsip/ spw/spw_position.php (accessed 9 July 2008) 